\title{
Yozgat ilinde yaşayan gebelerin sosyoekonomik ve demografik faktörler açısından değerlendirilmesi
}

\author{
Assessment of pregnants living in the province of Yozgat in relation with \\ socioeconomic and demographic factors
}

\author{
Mustafa Kara*, Emel Kıyak Çağlayan, Seyhan Karaçavuş, Yalçın Erdoğan \\ Kadın Hastalıkları ve Doğum Ana Bilim Dalı (Yrd. Doç. Dr. M. Kara, Dr. E. K. Çağlayan), \\ Nükleer Tıp Ana Bilim Dalı (Dr. S. Karaçavuş), Aile Hekimliği Ana Bilim Dalı (Dr. Y. Erdoğan), \\ Bozok Üniversitesi Tıp Fakültesi, TR-66200 Yozgat
}

\section{Özet}

Amaç. Bu çalışmanın amacı sosyoekonomik faktörler ile gebelik parametreleri arasındaki ilişkiyi göstermektir. Yöntemler. Kliniğimize Nisan 2011-Ekim 2011 arasında başvuran toplam 300 hasta kabul kriterlerine göre bu kesitsel çalışmaya dahil edildi. Katılan kadınlara yüz yüze görüşme metodu ile ayrıntılı bir anket uygulandı. Maternal yaş, eğitim düzeyi, maternal meslek, bulantıkusma durumu, beslenme sorunu, vitamin kullanımı, maternal kilo alımı, önceki doğumların sayısı, eş eğitim düzeyi, aylık gelir düzeyi, planlı gebelik durumu, sosyal sınıf, sigara içme ve alkol tüketimi değerlendirildi. Bulgular. Ailenin aylık gelir düzeyi gruplarına göre beslenme sorunu, planlı gebelik durumu, gebelikte vitamin kullanımı, maternal yaş, maternal meslek, eş mesleği ve aile tipi açısından istatistiksel olarak anlamlı farklılık gözlendi. Sonuç. Sosyoekonomik düzeyi düşük olan gebelerin gebelik parametreleri ve yaşam kalitesi skorları sosyoekonomik düzeyi yüksek olan gebelerden anlamlı şekilde daha düşüktü.

Anahtar sözcükler: Gebelik, sosyoekonomik seviye, maternal kilo alımı, eğitim

\begin{abstract}
Aim. The aim of this study is to demonstrate the association between socioeconomic factors and pregnancy parameters. Methods. A total 300 patients referred to our clinic between April 2011October 2011 were included into this cross sectional study according to the acceptance criteria. A detailed questionnaire was addressed to the participating women by face-to-face interview method. Maternal age, educational status, maternal occupation, presence of nausea-vomiting, nutrition issue, vitamin intake, maternal weight gain, number of previous births, husband's educational level, monthly income, status of planned pregnancy, social class, smoking, and alcohol consumption were evaluated. Results. There were statistically significant differences between the monthly income groups in relation with nutrition issue, planned pregnancy status, vitamin intake throughout pregnancy, maternal age, maternaloccupation, husband occupation, and family type. Conclusion. Pregnancy parameters and life-quality scores of the pregnants who have low socioeconomic level were significantly lower than pregnants with high socio-economic level.
\end{abstract}

Keywords: Pregnancy, socio-economic level, maternal weight gain, education

Geliş tarihi/Received: 13 Aralık 2011; Kabul tarihi/Accepted: 14 Mayıs 2012

\section{*İletişim adresi:}

Dr. Mustafa Kara, Kadın Hastalıkları ve Doğum Ana Bilim Dalı, Bozok Üniversitesi Tıp Fakültesi, TR-66200 Yozgat. E-posta: opdrmustafakara@ hotmail.com

\section{Giriş}

Maternal sosyoekonomik seviye ve onunla yakın ilişki içinde olan demografik ve kültürel faktörler gebelik sürecini, anne ve fetusu ciddi şekilde etkiler [1]. Gebelikteki beslenme 
ve kilo almanın gebelik sonuçları üzerine olan etkileri hakkındaki bilgilerimiz giderek artmaktadır [2]. Amerika Birleşik Devletleri'nde (ABD) fetal ve maternal mortalite hızının sosyoekonomik seviyenin daha kötü olduğu kadınlarda 4 kat fazla olduğu saptanmıştır [3]. Gözlemsel çalışmalar prenatal bakım alan ve almayan kadınların gebelikleri karşılaştırıldığında sosyoekonomik faktörler nedeniyle prenatal bakım alamayan hastalarda gebelik ve doğuma bağlı ciddi morbidite ve mortalite artış1 bildirilmesine rağmen randomize kontrollü araştırmalar prenatal bakımın doğum sonuçlarını iyileştirdiğine dair bir kanıt sunamamışırı [4, 5]. Prenatal bakım anneyi en az riskle sağlıklı bir doğum yapacak ortamı sunmayı hedefler. ABD'de 2006 y1lında tüm gebelerin \%83'ünün ilk trimesterde prenatal bakım aldığı, \%3,6'sının ise gebeliği boyunca hiç prenatal bakım almadığı bildirilmiştir [6]. Dünya Sağlık Örgütü (WHO) tüm gebelerin gebelikleri boyunca en az 4 kez prenatal bakım alması gerektiğini vurgulamaktadır [7]. Ülkemizdeki duruma gelince 2003 'te \%81 olan doğum öncesi bakım alma oranı 2008 yılında \%92'ye yükselmiştir. Gelir düzeyi düşük hanelerde yaşayan kadınların (\%76) doğum öncesi bakım alma oranı orta ve yüksek refah düzeyine sahip kadınlardan (\%98) istatistiksel olarak anlamlı düzeyde daha düşük bulunmuştur [8]. Bütün bu bilgilerin 1şığında, biz bu çalışma ile sosoyoekonomik düzey ile obstetrik parametreler ve demografik faktörler arasında bir ilişki olup olmadığını göstermeyi amaçladık.

\section{Gereç ve yöntem}

Kesitsel tipteki bu çalışmaya Nisan 2011-Ekim 2011 tarihleri arasında kliğimize başvuran ve gebelikleri sırasında danışma alan 300 kadın dahil edildi. Çalışma grubu olarak aile aylık gelir düzeylerine (AAGD) göre gelir düzeyi < 1000 TL olanlar Grup 1 (43 kişi) ve AAGD > 1000 TL olanlar Grup 2 (257 kişi) şeklinde sınıflandırıldı. Çalışmaya alınmama kriterleri kronik hastalık varlığı ve çoğul gebelik idi. Deneklerin sosyoekonomik, demografik ve kültürel verileri 21 sorudan oluşan bir anket yapılarak elde edildi (Tablo 1). Anket, deneyimli bir personel tarafindan özel bir ortamda ve yüz yüze görüşme yöntemi ile yapıldı. Her antenatal vizit sırasında hastaların son adet tarihi (SAT) ve ultrasonografik ölçümleri baz alınarak gebelik haftaları hesaplandı, kilo ölçümleri yapıldı ve gebeliğin ilk trimesterinde yapılan ölçüm ile doğumdan hemen önceki ağırlıklar karşılaştırılarak her bir gebenin ne kadar kilo aldığı hesaplandı. Ağırlık ölçümleri yapılırken işlemin ayakkabısız, ayakta ve herhangi bir yere tutunmadan aynı elektronik tartı üzerinde ve aynı kişi tarafından yapılmasına özen gösterildi. İstatistiksel analizler Statistical Package for Social Sciences (SPSS 17.00, SPSS Inc., Chicago, IL, USA) programı kullanılarak hesaplandı. Sayısal değişkenler ortalama \pm standart hata, sınıflandırılmış değişkenler ise sayı ve yüzde olarak ifade edildi. Tüm değişkenlere dağılım testleri uygulandıktan sonra normal dağılıma uyan sürekli değişkenler student-t testi, normal dağılıma uymayan değişkenler Mann-Whitney U testi ile karşılaştırıldı. Sınıflandırılmış değişkenlere ise $\chi^{2}$ (ki-kare) testi uygulandı. Analizler değerlendirilirken $\alpha$ anlamlılık düzeyi 0,05 olarak kabul edildi $(p<0,05)$. AAGD ile maternal demografik faktörler ve obstetrik özellikler arasındaki ilişki Tablo 2'de gösterilmiştir. Aylık gelir düzeyi $<1000$ TL olan 43 kişinin 20'sinde $(\% 46,5)$ beslenme sorunu mevcut iken, gelir düzeyi > 1000 TL olan 257 kişinin 56'sında $(\% 21,8)$ beslenme sorunu mevcut idi. Aile aylık gelir düzeyi (AAGD) ile beslenme sorunu arasında istatistiksel olarak anlamlı ilişki saptandı $(\mathrm{p}<0,001)$. AAGD ile yeme alışkanlıkları arasında anlamlı bir fark yoktu. Yine aynı şekilde AAGD ile gebelikte bulantı-kusma arasında fark yoktu. AAGD ile anne yaşı arasındaki ilişki anlamlı idi ( $\mathrm{p}<0,001)$. Grup 1'de 25 yaş altı gebelik oranı \%67,4 (29/43) iken grup 2'de aynı parametre \%38,5 (99/257) oranında gözlendi (Şekil 1).

\section{AAGD: Aile aylık gelir düzeyi}

AAGD ile eğitim durumu arasında fark yoktu. AAGD ile annenin mesleği arasındaki ilişki anlamlı idi. Gelir düzeyi < 1000 TL olanların \% 100’ü ev hanımı iken, geliri > 1000 TL olanların \%71,2'si $(183 / 257)$ ev hanımı idi $(\mathrm{p}<0,001)$. Gruplar arasında AAGD ile evlilik süresi ve gebelikte alınan kilo açısından anlamlı fark yoktu. 


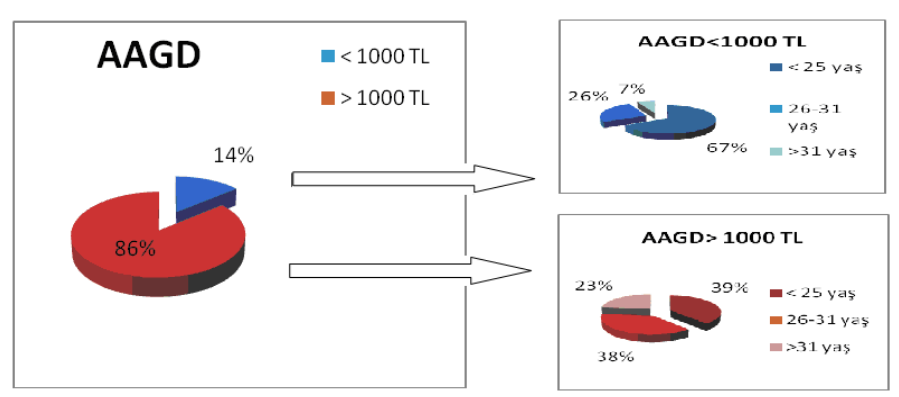

Şekil 1. Aile aylık geliri düzeyi ile maternal yaş arasındaki ilişki $(\mathbf{p}<0,001)$.

Tablo 1. Sosyoekonomik ve demografik özelliklerini değerlendirme anket formu.

\begin{tabular}{|c|c|c|}
\hline \multicolumn{3}{|l|}{ Adı-Soyadı } \\
\hline \multicolumn{3}{|l|}{ Telefon } \\
\hline \multicolumn{3}{|l|}{ Yaş } \\
\hline \multicolumn{3}{|l|}{ Eğitim durumu } \\
\hline Okur yazar/İlkokul & Ortaokul/Lise & Yüksekokul \\
\hline Ev Kadını & Çalışıyor & \\
\hline Evlilik süresi & $1-5$ y1l / 6-10 y1l & 11 yıldan fazla \\
\hline Eşinin eğitim durumu & Ortaokul/Lise & Yüksekokul \\
\hline \multicolumn{3}{|l|}{ Eşin mesleği } \\
\hline Kalifiye olmayan işçi & Memur & Serbest meslek \\
\hline Aile tipi & Çekirdek aile & Geniş aile \\
\hline Ailenizin toplam aylık geliri & 1000 TL alt1 & 1000 TL ve üzeri \\
\hline \multicolumn{3}{|l|}{ Kaç doğum yaptınız? } \\
\hline Küretaj oldunuz mu? & & \\
\hline \multicolumn{3}{|l|}{ Kaç haftalık gebesiniz? } \\
\hline Beslenme sorunu & Evet & Hayır \\
\hline Bulantı-Kusma & Var & Yok \\
\hline Gebeliğiniz planlanan bir gebelik mi? & Evet & Hayır \\
\hline Tedaviyle mi gebe kaldınız? & Evet & Hayır \\
\hline Doğum için planlanan bir tercihiniz var mı? & Normal doğum & Sezeryan doğum \\
\hline Vitamin ve mineral alıyor musunuz? & Evet & Hayır \\
\hline \multicolumn{3}{|l|}{ Gebelik süresince kaç kilo aldınız? } \\
\hline Rejim yapıyor musunuz? & Evet & Hayır \\
\hline Sigara içiyor musunuz? & Evet & Hayır \\
\hline Alkol alıyor musunuz? & Evet & Hayır \\
\hline
\end{tabular}

AAGD ile gebelikte vitamin kullanımı arasındaki ilişki değerlendirildiğinde grup 1'dekilerin \%58,1 (25/43), grup 2'dekilerin ise \%78,2'sinde (201/257) gebelik sirasinda vitamin kullanılmaktaydı ve arada istatistiksel olarak anlamlı fark vard1 $(\mathrm{p}<0,004)$. AAGD ile gebelikteki diyet, aşerme, sigara ya da alkol kullanımı arasında anlamlı bir ilişki yoktu. AAGD ile gebeliğin planlı bir gebelik olup olmaması arasındaki ilişki değerlendirildi. Grup 1'dekilerin \%67,4'ünde (29/43), grup 2'dekilerin ise \%80,9'unda (208/257) planlı gebelik saptand ve aradaki fark istatistiksel olarak anlamlı idi $(\mathrm{p}<0,040)$. AAGD ile tercih edilen doğum şekli ya da kıymetli gebelik olup olmaması arasında fark yoktu. AAGD ile eşin eğitim durumu arasında anlamlı ilişki saptandı $(\mathrm{p}<0,001)$. Grup 1'deki eşlerin \%27,9'u (12/43) ilkokul mezunu iken grup 2'deki eşlerin \%7,8'i (20/257) ilkokul mezunu idi. AAGD ile eşin mesleği arasındaki ilişki de istatistiksel olarak anlamlı idi (p<0,003). Grup 1'dekilerin \%53,4'ü (23/43) işçi iken grup 2'de aynı oran \%16,7 (43/257) idi. AAGD ile aile tipi arasında istatistiksel olarak anlamlı ilişki bulundu ( $<<0,001)$. Çekirdek aile oranı sırasıyla grup 1'de \%55,8 (24/43), grup 2'de \%80,5 (207/257) idi (Tablo 3). 
Tablo 2. Aile aylık geliri düzeyi ile maternal demografik faktörler ve obstetrik karakteristikler arasındaki ilişki.

\begin{tabular}{llll}
\hline & Grup 1 (n= 43) & Grup 2 (n= 257) & p değeri \\
\hline Maternal yaş, yıl (\%) & & & $<0,001$ \\
$<25$ & 67,4 & 38,5 & \\
$25-30$ & 25,6 & 38,1 & \\
$>30$ & 7,0 & 23,3 & $<0,460$ \\
\hline Yeme alışkanlığı (\%) & & & \\
Düzenli & 74,4 & 81,7 & \\
Düzensiz & 25,6 & 18,3 & $<0,230$ \\
\hline Bulantı-kusma (\%) & 65,1 & 56,4 & $<0,004$ \\
\hline Maternal vitamin kullanımı (\%) & 58,1 & 78,2 & $<0,530$ \\
\hline Gebelikte diyet (\%) & 0 & 1,6 & $<0,530$ \\
\hline Așerme (\%) & 39,5 & 33,5 & $<0.001$ \\
\hline Sigara (\%) & 7 & 8,2 & \\
\hline Beslenme sorunu (\%) & $\% 46.5$ & $\% 21.8$ & \\
\hline Annenin eğitim düzeyi (\%) & & & \\
İlköğretim & 30.2 & 21.4 & \\
Lise & 69.8 & 49.8 & \\
Üniversite & 0 & 28.8 & \\
\hline Annenin işi (\%) & & & \\
Ev hanımı & 100 & 71.2 & \\
Çalışıyor & 0 & 28.8 & \\
\hline
\end{tabular}

Tablo 3. Aile aylık geliri düzeyi ile aile özellikleri ve eşle ilgili faktörler arasındaki ilişki.

\begin{tabular}{llll}
\hline & Grup 1 (n= 43) & Grup 2 $(\mathbf{n = 2 5 7 )}$ & p değeri \\
\hline Planlı gebelik (\%) & 67,4 & 80,9 & $<0,040$ \\
\hline Kıymetli gebelik(\%) & 4,7 & 10,9 & $<0,161$ \\
\hline Doğum tercihi (\%) & & & $<0,736$ \\
NSD & 65,1 & 63,8 & \\
C/S & 34,9 & 36,2 & $<0,283$ \\
\hline Evlilik süresi, yıl (\%) & & & \\
$<1$ & 27,9 & 10,5 & \\
$1-5$ & 34,9 & 47,5 & \\
$5-10$ & 30,2 & 26,8 & \\
$>10$ & 7,0 & 15,2 & $<0,001$ \\
\hline Aile tipi (\%) & & & \\
Çekirdek aile & 55,8 & 80,5 & \\
Geniş aile & 44,2 & 19,5 & \\
\hline Eşin eğitim durumu & & & \\
Ilköğretim & 27,9 & 7,8 & \\
Lise & 58,1 & 45,5 & \\
Üniversite & 14,0 & 45,1 & \\
\hline Eşin mesleği & & & \\
Kalifiye işçi & 34,9 & 15,2 & \\
İşçi & 18,6 & 1,6 & \\
Memur & 0 & 38,9 & \\
Serbest meslek & 46,5 & 44,4 & \\
\hline
\end{tabular}

\section{Tartışma}

Bu çalışmadaki veriler bütün bir toplumu yansıtmasa da Yozgat ili genelindeki kentsel ve kırsal kesimi temsil ettiği göz önünde bulundurulacak olursa popülasyon bazlı bir çalışma olduğu söylenebilir. Doğum öncesi bakım sosyoekonomik ve kültürel değişkenlerden fazlasıyla etkilenir. Ancak, sosyoekonomik farklılıkların obstetrik parametrelerle ve kültürel bileşenlerle ne derece birliktelik gösterdiği tam olarak bilinmemektedir. Bu nedenle, bu çalışma özellikle sosyoekonomik seviyesi iyi olan gebelerle iyi olmayan 
gebelerin obstetrik, demografik ve kültürel farklılıklarını göstermesi bakımından önemlidir. Anne ölümleri gelişmekte olan ülkelerde gelişmiş ülkelere göre daha fazla görülmektedir. Afrika'da maternal sebeplere bağlı ölüm riski 16'da 1 iken Batı Avrupa'da 4000'de 1'dir. Bu ölümlerin büyük çoğunluğu önlenebilir nedenlere bağlı olup doğum öncesi, doğum ve doğum sonrası bakım eksikliğinden kaynaklanmaktadır. Anne ölümlerinin \%70'i yalnızca 13 ülkede görülmektedir [9]. Dünya Sağlık Örgütü verilerine göre her y1l 500.000'den fazla kadın gebelik veya doğum nedeniyle hayatını kaybetmekte ve çoğu kadın hasta ve sakat kalmaktadır [10]. Çalışmamızda $<25$ yaş gebelik oranı AAGD $<1000 \mathrm{TL}$ olan grupta \%67,4 iken AAGD > $1000 \mathrm{TL}$ olan grupta \%38,5'tir $(\mathrm{p}<0,001)$. İki grup arasındaki bu fark sosyoekonomik seviyesi düşük olan ailelerde erken yaşta yapılan evliliklere ve bu evlilikler sonucunda meydana gelen gebeliklere bağlı olabilir. Ayrıca, bu erken yaştaki evlilikler ve onlara bağlı olarak oluşan gebelikler eğitim ve iş firsatlarının da önüne geçebilir. Gerçekten de bizim çalışmamızda maddi durumu düşük olan grup 1'deki hastaların tamamı (\%100) ev hanımı iken, maddi durumu daha iyi olan grup 2'deki hastaların \%71,2'si ev hanımı idi $(\mathrm{p}<0,001)$. Eğitim açısından karşılaştırıldığında, her iki grup arasında anlamlı bir fark olmasa da grup 1'de eğitim düzeyi grup 2'den daha düşüktü $(p=0,491)$. Eşin eğitim düzeyi açısından karşılaştırıldığında düşük sosyoekonomik seviyeli grupta ilköğretim okulundan mezun olma oranı diğer gruba göre anlamlı şekilde daha fazla idi (\%27,9'a karşı \%7,8, p<0,001). Daha da ötesi, bu tür zor koşullar kadınları muhtemel bir anne adayı olarak planlı bir gebeliğe karşı hazırlıksız kılar [11]. Bizim çalışmamızda planlı gebelik oranı sırasıyla grup 1 için $\% 67,4$, grup 2 için ise $\% 80,9$ olarak bulunmuştur $(p=0,04)$. Çalışmamızda çekirdek aile oranı grup 1'de grup 2'ye göre anlamlı şekilde daha düşüktü (\%55,8'e karş1 $\% 80,9, \mathrm{p}<0,001)$. Görüldüğü gibi sosyoekonomik seviyesi düşük olan kadınlar eğitimi yarıda bırakma, işsizlik ve sosyal izolasyon açısından daha fazla risk altındadır. Bu koşullar altında gelişecek bir gebelik anne ve fetusu negatif yönde etkileyebilir. Sosyoekonomik seviyesi düşük olan hastalardaki gebeliklerin olumsuz sonuçlandiğı bildirilmiştir $[12,13]$. Katılımcı sayısının az olması, kesitsel tipte bir çalışma olması, bölgenin sosyokültürel yapısı nedeniyle alkol tüketimi gibi bazı değişkenlere yanıtın bölgeye özgü olması çalışmamızdaki kısıtlayıcı faktörlerdir.

Sonuç olarak, riskli gebeliklerin erken tespiti ve tedavisi, ölü doğumların ve bebek ölümlerinin önlenebilmesi, anne ve bebek sağlığının korunması için doğum öncesi bakım hizmetlerinin koruyucu sağlık hizmetleri kapsamında yeterli ve nitelikli verilmesi hayati önem taşımaktadır. Sosyoekonomik seviye annenin yaşı, anne ve eşin eğitim düzeyi ve aile tipi ile yakın ilişki içindedir. Bu nedenle, sosyoekonomik seviyesi düşük ailelere verilecek olan doğum öncesi bakım daha bir önem taşır.

\section{Kaynaklar}

1. Morgen CS, Bjørk C, Andersen PK, Mortensen LH, Nybo Andersen AM. Socioeconomic position and the risk of preterm birth--a study within the Danish National Birth Cohort. Int J Epidemiol 2008; 37: 1109-20.

2. Tuntiseranee P, Olsen J, Chongsuvivatwong V, Limbutara S. Socioeconomic and work related determinants of pregnancy outcome in southern Thailand. J Epidemiol Community Health 1999; 53: 624-9.

3. Ventura SJ, Martin JA, Curtin SC, Mathews TJ, Park MM. Births: Final data for 1998. National Vital Statistics Report 2000; 48.

4. The Management of Uncomplicated Pregnancy Working Group. DoD/VA Clincial Practice Guideline for the Management of Uncomplicated Pregnancy. Washington, DC: Department of Defense and Veterans Administration, 2002.

5. The Cochrane Library. Does prenatal care improve birth outcomes: A critical review. Database of Abstracts of Reviews of Effects 2006; 4.

6. Martin, JA, Hamilton, BE, Sutton, PD, et al. Births: final data for 2006. Natl Vital Stat Rep 2009. Available at www.cdc.gov/nchs/data/nvsr/nvsr57/nvsr57_07.pdf. (accessed on May 15, 2012). 
7. WHO antenatal care randomized trial: manual for implementation of the new model. Geneva, World Health Organization, 2002 (document WHO/RHR/01.30) (http://http://whqlibdoc.who.int/hq/2001/WHO_RHR_01.30.pdf, accessed on May 15, 2012).

8. Hacettepe Üniversitesi Nüfus Etütleri Enstitüsü (2009) Türkiye Nüfus ve Sağlik Araştırmas1, 2008. Hacettepe Üniversitesi Nüfus Etütleri Enstitüsü, Sağlık Bakanlığı Ana Çocuk Sağlığı ve Aile Planlaması Genel Müdürlüğü, Başbakanlık Devlet Planlama Teşkilatı Müsteşarlığı ve TÜBİTAK, Ankara, Türkiye.

9. Maternal mortality in 2000: estimates developed by WHO, UNICEF and UNFPA. WHO. Geneva: 2003. http:// http://whqlibdoc.who.int/hq/2000/a81531. (accessed on May 15, 2012).

10. World Health Day, Safe Motherhood, Maternal Mortality, World Health Organization CH-1211 Geneva 27 Switzerland 1998: 1651.

11. Klima CS. Centering pregnancy: a model for pregnant adolescents. J Midwifery Womens Health 2003; 48: 220-5.

12. Koniak-Griffin D, Turner-Pluta C. Health risks and psychosocial outcomes of early childbearing: a review of the literature. J Perinat Neonatal Nurs 2001; 15: 117.

13. Pathak PK, Singh A, Subramanian SV. Economic Inequalities in Maternal Health Care: Prenatal Care and Skilled Birth Attendance in India, 1992-2006. Plos One 2010; 5: e13593. 